\title{
Metabolic syndrome and risk factors for cardiovascular disease in obese children: the relationship with insulin resistance (HOMA-IR)
}

\author{
Aparecido Pimentel Ferreira, ${ }^{1}$ Carlos E. R. Oliveira, ${ }^{2}$ Nancí Maria França ${ }^{3}$
}

\begin{abstract}
Objective: To identify the prevalence of metabolic syndrome and risk factors for the development of cardiovascular diseases and to investigate their relationship with insulin resistance.

Methods: This was a cross-sectional study of 52 obese children. The sample was chosen at random after the body mass index [weight $(\mathrm{kg}) /$ stature $(\mathrm{m})^{2}$ ] of 1,550 schoolchildren had been calculated. Children were defined as obese when their BMI was above the 95th percentile of the Centers for Disease Control and Prevention classification. Blood samples were taken after fasting and glycemia, high-density lipoproteins, triglycerides and insulin were all assayed. Body fat was evaluated using dual energy $X$-ray absorptiometry. Arterial blood pressure and insulin resistance were also measured. Metabolic syndrome was defined according to National Cholesterol Education Program criteria, with cutoff points adjusted for the age of the sample.

Results: Metabolic syndrome was detected in $17.3 \%$ of the children investigated. Insulin resistance was significantly different for females $(3.8 \pm 2.2 ; 95 \% \mathrm{CI} 2.9-4.8)$ and males $(2.6 \pm 1.3 ; 95 \% \mathrm{CI} 2.1-3.1) ; \mathrm{p}=0.016$. Around $44.2 \%$ of the sample exhibited at least two risk factors, and $15 \%$ exhibited arterial hypertension. Hypertriglyceridemia was observed in 50 and $70.8 \%$ of boys and girls, respectively. Lower than desirable high-density lipoprotein levels were only observed among the girls.
\end{abstract}

Conclusions: Obese children exhibited a high prevalence of metabolic syndrome. The children with greater insulin resistance exhibited more risk factors. In the light of these findings intervention measures are necessary in order to prevent excessive weight gain during childhood.

J Pediatr (Rio J). 2007;83(1):21-6: Child, obesity, metabolic syndrome.

\section{Introduction}

Reaven et al. described the metabolic syndrome (MS), explaining the link between insulin resistance and arterial

1. Mestrando em Atividade Física e Saúde, Universidade Católica de Brasília (UCB), Brasília, DF, Brasil.

2. Graduando em Educação Física, Bolsista de iniciação científica, UCB, Brasília, DF, Brasil.

3. Doutora, UCB, Brasília, DF, Brasil.

Manuscript received Mar 13 2006, accepted for publication Aug 022006.

Suggested citation: Ferreira AP, Oliveira CE, França NM. Metabolic syndrome and risk factors for cardiovascular disease in obese children: the relationship with insulin resistance (HOMA-IR). J Pediatr (Rio J). 2007;83(1):21-6.

doi 10.2223/JPED.1562 hypertension, dyslipidemia, type 2 diabetes mellitus (DMT2) and other metabolic anomalies associated with cardiovascular diseases (CVD) in adults. However, nowadays this problem is observed with ever greater frequency among children, particularly those with excess body mass.

In addition to identifying obesity as an independent risk factor for CVD in pediatric populations, several studies have also demonstrated strong links between MS and many comorbidities and pathologies, such as insulin resistance, hyperinsulinemia, arterial hypertension, dyslipidemia and DMT2. ${ }^{1-4}$

Over recent decades a process of nutritional transition has been observed. Comparing data from the National 
Survey on Household Expenses (ENDF - Estudo National de Despesa Familiar), carried out in 1974/1975, with data from the Living Standards Survey (PPV - Pesquisa sobre Padrões de Vida), undertaken in 1996/1997 and restricted to the Southeast and Northeast regions of Brazil, increases are observed in the prevalence of overweight and obesity from 4.1 to $13.9 \%$, among children and adolescents from 6 to 18 years. ${ }^{5}$ Studies undertaken in specific Brazilian cities demonstrate that overweight and obesity already affect more than $20 \%$ of children and adolescents; in Recife, for example, $35 \%$ of the schoolchildren assessed had excess weight. ${ }^{6}$

More recently, even more alarming rates of overweight and obesity have been observed in both the USA and Brazil, with 26 and $10 \%$ of rural and 25 and $19 \%$ of urban populations affected respectively. ${ }^{7}$

Epidemiological studies have demonstrated an association between the growing incidence of chronic diseases, such as DMT2 and coronary disease, with reduced length of disease-free life, in line with increases in body mass index (BMI) and concomitant with populational hyperinsulinemia. ${ }^{8-11}$

Against this background, this study was carried out with the objective of identifying the prevalence of MS in obese children from 7 to 11 years of age, in addition to analyzing whether increased insulin resistance correlates with more risk factors for developing CVD in later life.

\section{Methods}

This was a cross-sectional, population-based, epidemiological study, the initial sample for which was obtained at random, respecting a confidence interval (CI) of $97 \%$, from public and private schools in the satellite town Taguatinga, Brasília, DF. Schools and classes were chosen at random, taking care to preserve the proportion of students enrolled in each educational segment.

After screening 1,550 children from 7 to 10 years of age (958 from 10 public schools and 592 from four private schools), we detected 124 (8\%) obese children, 74 (7.7\%) of whom studied at public schools. After being invited to undergo a battery of tests, 52 obese children agreed to take part in the study. Since very few children from private schools agreed to take part, this sector was excluded from the sample.

The study was approved by Ethics Committee at the Universidade Católica de Brasília and by the Regional Education Department of Taguatinga. The parents of those assessed signed a free and informed consent form allowing their children to take part.
Initial screening examinations were performed using a stadiometer accurate to $1 \mathrm{~mm}$, Seca brand, to measure height, and a Plena brand digital balance to measure weight with $100 \mathrm{~g}$ resolution, following a measurement protocol described by Marins \& Giannichi. ${ }^{12}$ Body mass index was calculated by dividing weight $(\mathrm{kg})$ by the square of height $(\mathrm{m})$, and children were classified as obese if their BMI was above the 95th percentile on the classification published by the Centers for Disease Control (CDC), as recommended by the World Health Organization. The 52 children whose parents signed the free and informed consent form and who agreed to the supplementary tests had their weight and height measured again and their waists were measured at the height of the umbilical scar. Arterial blood pressure was measured by the auscultatory method, using a sphygmomanometer, Premium brand, with a suitable cuff size for each patient, after 5 minutes' rest in the supine position and again approximately 25 minutes after the first reading. Arterial blood pressure was considered the mean of the two measurements. Children were defined as hypertense if their blood pressure was over the 95th percentile for their age, sex and height. Systolic (SBP) and diastolic (DBP) pressures corresponding to the first and fifth Korotkoff sounds were measured.

The children's chronological ages were determined centesimally, using date of birth and date of measurements to define age groups.

Body fat was measured using dual energy X-ray absorptiometry (DXA). Volunteers were requested to remove any metallic items they were wearing, such as rings, jewelry, belts and watches (due to the fact that such objects affect the values of the estimated variables). Next, volunteers were placed in horizontal decubitus dorsal on the DXA apparatus for full-body analysis. The pediatric analysis option on the apparatus was selected and the manufacturer's recommendations were followed. The equipment used was a Lunar DPX-IQ with version $4.6 \mathrm{~A}$ software. Bone mineral content, muscle mass, and fat mass were estimated by segment and total body fat was quantified in both relative (percentage body fat) and absolute terms ( $\mathrm{kg}$ per body region), although only the body fat data have been used for this study. Before use the DXA equipment was duly calibrated, according to the manufacturer's recommendations, and cut line adjustments were predefined. All analyses were performed by the same assessor.

Blood samples were taken at the University Hospital at the Universidade Católica de Brasília, and for biochemical analyses a 12-hour fasting period was observed. Samples were collected in vacuum tubes with separator gel and without anticoagulant. After collection, blood was 
centrifuged for 10 minutes at 3,000 rpm to separate serum from the remaining components, with analyses being run on serum. Cholesterol, triglycerides, high-density lipoproteins (HDL) and glucose were assayed using an enzymatic colorimetric kit processed in Autohumalyzer A5 (Human, 2004). Insulin was assayed using the ACS-180 Automated Chemiluminescence System (Ciba-Corning Diagnostic Corp., 1995, USA).

\section{Diagnostic criteria}

Metabolic syndrome was diagnosed according to a modified version of the National Cholesterol Education Program's Adult Treatment Panel III (NCEP-ATP III), the same used for the First Brazilian Directive on the Prevention and Treatment of Metabolic Syndrome (I-DBSM, 2004 - I Diretriz Brasileira de Prevenção e Tratamento da Síndrome Metabólica), ${ }^{13}$ which consists of the presence of at least three of the following factors: obesity (characterized by abdominal obesity), dyslipidemia (high levels of triglycerides or low HDL levels), arterial hypertension and fasting hyperglycemia; the presence of DMT2 did not exclude a diagnosis of MS. However, cutoff points were adapted for the age of the study population: triglycerides $\geq$ $110 \mathrm{mg} / \mathrm{dL}, \mathrm{HDL} \leq 38 \mathrm{mg} / \mathrm{dL}$ and arterial hypertension (diastolic or systolic) > 95th percentile adjusted for age, height and sex. ${ }^{14}$ Fasting glycemia was established as from 100 to $126 \mathrm{mg} / \mathrm{dL}$, in accordance with American Diabetes Association recommendations (ADA, 2005). ${ }^{15}$ Obesity was defined as BMI above the 95 th percentile. ${ }^{16}$

Insulin resistance was detected by means of the homeostasis model for assessment of insulin resistance (HOMA-IR), which is the product of fasting insulin $(\mu \mathrm{UI} / \mathrm{mL})$ and fasting glycemia ( $\mathrm{mmol} / \mathrm{L})$ divided by $22.5 .{ }^{17}$

\section{Statistical analysis}

Data are presented in the form of means and standard deviations. Data analysis employed descriptive statistics (95\%CI) and the $t$ test for independent measures for comparisons of weight, height, BMI and centesimal age between sexes. One-way ANOVA, with Scheffé post-hoc, was used in order to compare the mean results for children classified as within insulin resistance Tertiles. The chi-square test was used to compare proportions between prevalence rates of the risk factors observed and absolute and percentage MS incidence rates. Data were analyzed using the SPSS 11.5 statistical package (SPSS Inc., Chicago, IL, USA).

\section{Results}

Fifty-two children classified as obese (BMI > 95th percentile/age) took part in the study, 28 of whom were male and 24 of whom were female. The mean age of participants was $9.2 \pm 1.4$ years for the boys and $9.3 \pm 1.4$ years for the girls. Further anthropometric and metabolic data are shown in Table 1.

Insulin levels were significantly different between the sexes, with girls having higher concentrations (17.8 \pm 9.9 $\mu \mathrm{UI} / \mathrm{mL}, 95 \% \mathrm{CI} 13.6-22)$ than boys $(11.9 \pm 5.7 \mu \mathrm{UI} / \mathrm{mL}$, 95\%CI 9.7-14.1); $[F=6.2:(1) ; p=0.011]$. Insulin resistance, measured by HOMA-IR, also differed significantly by sex, with higher values once more observed among females $(3.8 \pm 2.2,95 \% \mathrm{CI} 2.9-4.8)$ than among males $(2.6 \pm 1.3,95 \%$ CI 2.1-3.1); $[F=6.2:(1) ; p=0.016]$. The remaining variables did not differ between boys and girls.

Arterial hypertension (systolic or diastolic) was present in $14.3 \%$ of the boys and $16.7 \%$ of the girls. Hypertriglycidemia was present in 50 and $70.8 \%$ of boys and girls, respectively. None of the male children exhibited HDL levels lower than desirable, however, $12.5 \%$ of the girls had low HDL levels.

Only $78.6 \%$ of the boys and just $45.8 \%$ of the girls did not exhibit fasting insulin disorders, since $14.3 \%$ of the boys and $16.7 \%$ of the girls had pre-hyperinsulinemia (fasting plasma insulin levels $>15 \mu \mathrm{UI} / \mathrm{mL}$ ) and $7.1 \%$ of the boys and $37.5 \%$ of the girls already had hyperinsulinemia (fasting plasma insulin levels $>20 \mu \mathrm{UI} / \mathrm{mL}$ ).

Of the total of 52 children assessed, $17.3 \%$ met the modified NCEP and I-DBSM diagnostic criteria and were classified as having MS, being $10.7 \%$ males and $25 \%$ females.

Tables 2 and 3 contain absolute and percentage numbers of children exhibiting one, two, three and four risk factors for the development of CVD and a diagnosis of MS, represented in the form of general data and broken down by sex and by insulin resistance Tertiles, according to HOMA-IR ratios.

\section{Discussion}

This study of obese children over the 95th percentile on the CDC BMI/age scale has shown that a large proportion of these children already exhibit at least one more risk factor for the development of CVD in addition to obesity. Obesity is itself considered an independent risk factor for the development of CVD ${ }^{18}$ and is one of the diagnostic criteria for MS. Table 2 contains absolute and percentage numbers of children with one, two, three and four risk factors for the development of CVD and a diagnosis of MS. None of the children were diagnosed as having abnormal fasting glycemia, since, according to Weiss et al., this disorder is very rare among children, even when overweight. ${ }^{19}$ Although hyperinsulinemia is considered by many to be a 
risk factor for CVD ${ }^{9-11,20,21}$ and was diagnosed in $21.2 \%$ of the children studied here, it is not included in Table 2, since it is not one of the criteria adopted for the diagnosis of MS in this study.

The HOMA-IR index, which gauges insulin resistance by means of a mathematical equation employing fasting insulin and fasting glycemia figures, was elevated in both boys and girls. The children's HOMA-IR results were split into Tertiles and it was observed the greater the level of insulin resistance as expressed by HOMA-IR, the greater the number of risk factors for the development of CVD, in agreement with the results of other studies. ${ }^{10,19,21-24}$ Overall, those children whose insulin resistance levels fell into the first Tertile exhibited a statistically significantly lower number of risk than those in the third Tertile $\left[X^{2}=11.188 ;(1), p=0.001\right]$ (data shown in Table 3 ). Nevertheless, the mean HOMA-IR levels observed in this study were higher than those found by a study evaluating normal weight, overweight and obese Argentinian children, where the highest mean value observed in obese children was 2.76. ${ }^{10}$ The higher level of insulin resistance observed in this study could be the result of the greater level of obesity observed in the children studied here. Notwithstanding, other factors that were not measure may also have made strong contributions to this system, such as increased duration of exposure to obesity and nutritional questions issues.

Table 1 - Anthropometric, metabolic and hemodynamic characteristics of the study population

\begin{tabular}{|c|c|c|c|}
\hline & Male (28) & Female (24) & Total (52) \\
\hline Centesimal age (years) & $\begin{array}{c}9.2 \pm 1.4 \\
95 \% \mathrm{CI} 8.7-9.8\end{array}$ & $\begin{array}{c}9.3 \pm 1.42 \\
95 \% \text { CI } 8.7-9.9\end{array}$ & $\begin{array}{c}9.2 \pm 1.4 \\
95 \% \text { CI } 8.9-9.6\end{array}$ \\
\hline Weight (kg) & $\begin{array}{c}45.6 \pm 9.1 \\
95 \% \mathrm{CI} 42.1-49.1\end{array}$ & $\begin{array}{c}49.5 \pm 14 \\
95 \% \text { CI } 43.6-55.4\end{array}$ & $\begin{array}{c}47.4 \pm 11.7 \\
95 \% \text { CI } 44.1-50.6\end{array}$ \\
\hline BMI $\left(\mathrm{kg} / \mathrm{m}^{2}\right)$ & $\begin{array}{c}23.5 \pm 2.4 \\
95 \% \text { CI } 22.6-24.4\end{array}$ & $\begin{array}{c}24.7 \pm 3.9 \\
95 \% \text { CI } 23.1-26.4\end{array}$ & $\begin{array}{c}24.1 \pm 3.2 \\
95 \% \text { CI } 23.2-25\end{array}$ \\
\hline Waist (cm) & $\begin{array}{c}76.5 \pm 7.7 \\
95 \% \text { CI } 73.5-79.5\end{array}$ & $\begin{array}{c}79.1 \pm 9.8 \\
95 \% \text { CI } 74.9-83.2\end{array}$ & $\begin{array}{c}77.7 \pm 8.8 \\
95 \% \text { CI } 75.3-80.1\end{array}$ \\
\hline $\mathrm{SBP}(\mathrm{mmHg})$ & $\begin{array}{c}104.7 \pm 9.6 \\
95 \% \text { CI } 101-108\end{array}$ & $\begin{array}{c}108 \pm 17 \\
95 \% \text { CI } 100-115\end{array}$ & $\begin{array}{c}106.1 \pm 13.5 \\
95 \% \text { CI } 102-110\end{array}$ \\
\hline $\mathrm{DBP}(\mathrm{mmHg})$ & $\begin{array}{c}65 \pm 91 \\
95 \% \text { CI } 61.4-68.8\end{array}$ & $\begin{array}{c}66 \pm 15 \\
95 \% \mathrm{CI} 60-73\end{array}$ & $\begin{array}{c}65.7 \pm 12.3 \\
95 \% \text { CI } 62-69\end{array}$ \\
\hline DXA (\%) & $\begin{array}{c}38.4 \pm 4.1 \\
95 \% \text { CI } 36.8-40\end{array}$ & $\begin{array}{c}42.1 \pm 6.3 \\
95 \% \text { CI } 39.5-44.8\end{array}$ & $\begin{array}{c}40.1 \pm 5.5 \\
95 \% \text { CI } 38.6-41.7\end{array}$ \\
\hline Triglycerides (mg/dL) & $\begin{array}{c}112.2 \pm 44.5 \\
95 \% \text { CI } 95-129.5\end{array}$ & $\begin{array}{c}126 \pm 43.2 \\
95 \% \text { CI } 107.7-144.2\end{array}$ & $\begin{array}{c}118.6 \pm 44 \\
95 \% \text { CI } 106.3-130.8\end{array}$ \\
\hline $\mathrm{HDL}(\mathrm{mg} / \mathrm{dL})$ & $\begin{array}{c}53.2 \pm 6.3 \\
95 \% \text { CI } 50.7-55.6\end{array}$ & $\begin{array}{c}49.2 \pm 7.4 \\
95 \% \text { CI } 46-52.3\end{array}$ & $\begin{array}{c}51.3 \pm 7.1 \\
95 \% \text { CI } 48.4-53.3\end{array}$ \\
\hline Insulin $(\mu \mathrm{UI} / \mathrm{mL})$ & $\begin{array}{c}11.9 \pm 5.7 * \\
95 \% \text { CI } 9.7-14.1\end{array}$ & $\begin{array}{c}17.8 \pm 9.9 \\
95 \% \text { CI } 13.6-22\end{array}$ & $\begin{array}{c}14.6 \pm 8.4 \\
95 \% \text { CI } 12.3-17\end{array}$ \\
\hline Glycemia (mg/dL) & $\begin{array}{c}87.2 \pm 5.6 \\
95 \% \text { CI } 85-89.4\end{array}$ & $\begin{array}{c}86.5 \pm 5.1 \\
95 \% \text { CI } 84.4-88.7\end{array}$ & $\begin{array}{c}86.9 \pm 5.3 \\
95 \% \text { CI } 84.4-88.4\end{array}$ \\
\hline HOMA-IR & $\begin{array}{c}2.6 \pm 1.3+ \\
95 \% \text { CI } 2.1-3.1\end{array}$ & $\begin{array}{c}3.8 \pm 2.2 \\
95 \% \mathrm{CI} 2.9-4.8\end{array}$ & $\begin{array}{c}3.2 \pm 1.9 \\
95 \% \text { CI } 2.6-3.7\end{array}$ \\
\hline
\end{tabular}

$95 \% \mathrm{Cl}=95 \%$ confidence interval; $\mathrm{BMI}=$ body mass index; $\mathrm{DBP}=$ diastolic blood pressure; $\mathrm{DXA}=$ dual energy X-ray; $\mathrm{HDL}=$ high-density lipoproteins; HOMA-IR = homeostasis model for assessment of insulin resistance; SBP = systolic blood pressure.

${ }^{*} p=0.013 ; \dagger p=0.026$

Table 2 - Absolute and percentage numbers of children with from one to four cardiovascular risk factors and a diagnosis of metabolic syndrome

\begin{tabular}{lccc}
\hline & & Risk factors \\
\cline { 2 - 4 } & $\mathbf{1}$ factor & 2 factors & $\mathbf{3}$ factors \\
\hline Male & $13(46.4 \%)$ & $3(10.7 \%)$ & $\mathbf{4}$ factors \\
Female & $7(29.2 \%)$ & $12(42.9 \%)$ & $5(20.8 \%)$ \\
Total & $20(38.5 \%)$ & $23(44.2 \%)$ & $8(15.4 \%)$ \\
\hline
\end{tabular}

Cardiovascular risk factors were: obesity, hypertriglyceridemia, low levels of high-density lipoproteins, fasting hyperglycemia and arterial hypertension. 
Furthermore, a study carried out in the USA ${ }^{19}$ that evaluated 439 obese, 31 overweight and 20 normal weight children using the same method as the current study to measure insulin resistance found higher levels, with mean levels of 3.12 for overweight children, 7.05 for the moderately obese and 8.69 for severely obese and children. This demonstrates that the interaction of several factors (nutritional factors, duration of obesity and quantity of body fat) may cause greater insulin resistance. We suggest the nutritional influence considering that the values observed in obese children in the current study were similar to values observed in children classed as overweight in the United States. Quantity of body fat is included because the North American children classified as moderately and severely obese exhibited higher percentages of body fat than those described here.

However, another possible explanation for insulin resistance in children, and one that is the subject of much research, ${ }^{3,4,9,10,18}$ is high levels of abdominal fat deposition, which are probably greater in these children who exhibit increased body fat, since this type of fat has a high degree of correlation with body fat.

The prevalence of children suffering from MS was $17.3 \%$, broken down as $10.7 \%$ of the boys and $25 \%$ of the girls. These figures are comparable with the results of another study, ${ }^{25}$ that analyzed schoolchildren from a rural community in the USA and found figures of $10 \%$ for boys and $18 \%$ for girls aged 7 to 18 years. Also in agreement with our study are the results of the Bogalusa Heart Study, ${ }^{26}$ which found that $17.2 \%$ of children aged 5 to 10 years exhibited three or more risk factors for CVD.

These results indicate that one factor that should be monitored in obese children is their resistance to insulin resistance, since it appears that the greater the level of insulin resistance, the greater the number of cardiovascular

Table 3 - Absolute and percentage numbers of obese children with cardiovascular risk factors and a diagnosis of metabolic syndrome, classified by insulin-resistance Tertiles

\begin{tabular}{lcccc}
\hline \multirow{2}{*}{$\begin{array}{l}\text { HOMA-IR } \\
\text { tertile }\end{array}$} & \multicolumn{4}{c}{ Cardiovascular risk factors } \\
\cline { 2 - 5 } & $\mathbf{1}$ factor & $\mathbf{2}$ factors & $\mathbf{3}$ factors & $\mathbf{4}$ factors \\
\hline Tertile $1 *$ & $10(58.8 \%)$ & $7(41.2 \%)$ & \\
Tertile $2 *$ & $8(47.1 \%)$ & $6(35.3 \%)$ & $3(17.6 \%)$ & \\
Tertile $3+$ & $2(11.1 \%)$ & $10(55.6 \%)$ & $5(27.8 \%)$ & $1(5.6 \%)$ \\
\hline HOMA-IR = homeostasis model for assessment of insulin resistance. & \\
Tertile 1 = mean of $1.5 \pm 0.4,95 \% \mathrm{Cl} 1.3-1.7 ;$ Tertile $2=$ mean of $2.7 \pm 0.4,95 \% \mathrm{Cl}$ \\
2.5-2.9; Tertile $3=$ mean of $5.2 \pm 1.6,95 \% \mathrm{Cl} 4.4-6$. \\
${ }^{*} \mathrm{p}=0.005 ; \dagger \mathrm{p}<0.001$.
\end{tabular}

risk factors, the higher the prevalence of MS and, consequently, the greater the risk of premature development of DMT2 and CVD. Furthermore, studies that have detected increased levels of insulin resistance also observed higher prevalence rates of MS, when compared with the present study. ${ }^{19,22}$

Insulin resistance is a reduction in the capacity of insulin to stimulate glucose use, whether due to a deficiency in the insulin receptor, a reduction in the concentration of receptors, a failure of the cellular transport mechanism or a defect in certain post-reception mechanisms. As a result of insulin resistance, pancreas $\beta$-cells increase insulin production and secretion as a compensatory mechanism (hyperinsulinemia), while glucose tolerance remains normal. This state continues for some time, until a decline is observed in insulin secretion and, consequently, a reduction in glucose tolerance. ${ }^{3}$

Hyperinsulinemia is considered an independent risk factor for CVD, since it plays an important role in the development of other components of MS, such as dyslipidemia, hypertension and hyperuricemia. Bao et al. performed a longitudinal study investigating the plasma insulin levels of children from 5 to 9 years of age and observed the consequences of elevated levels for lipids profiles and blood pressure. Similarly, the current study also observed elevated levels of plasma insulin, accompanied by arterial hypertension and an unfavorable lipids profile, in obese children, which could be indicative that insulin resistance may be taking hold in some of the obese children, triggering off others of the factors that comprise a diagnosis of MS and exposing them to further risk factors.

Other studies have reported percentage values for MS prevalence. Comparisons are, however, difficult since some of these studies worked with the general population, others used samples containing only overweight or obese children and others employed different definitions or cutoff points. $22,24,27,28$

\section{Conclusions}

The results of this study show that obese children exhibit several risk factors for the development of CVD and that MS is already a reality for many children, being present in $17.3 \%$ of the obese children investigated here. This could lead to earlier onset of DMT2 and atherosclerotic diseases.

We can also observe that the higher the number of risk factors present in obese children, the greater their propensity to progress to a future diagnosis of MS, DMT2 and CVD. 
This study has demonstrated that there are many metabolic complications present in obese children and that intervention actions are needed to put a brake on excess weight during childhood.

\section{References}

1. Reaven GM. Banting lecture 1988. Role of insulin resistance in human disease. Diabetes. 1988;37:1595-607.

2. Cruz ML, Weigensberg MJ, Huang TT, Ball G, Shaibi GQ, Goran MI. The metabolic syndrome in overweight Hispanic youth and the role of insulin sensitivity. J Clin Endocrinol Metab. 2004;89:108-13.

3. Oliveira CL, Mello MT, Cintra IP e Fisberg M. Obesidade e síndrome metabólica na infância e adolescência. Rev Nutr Campinas. 2004; 17:237-45.

4. Miranda PJ, Defronzo RA, Califf RM, Guyton JR. Metabolic syndrome: definition, pathophysiology, and mechanisms. Am Heart J. 2005;149:33-45.

5. Wang Y, Monteiro C, Popkin BM. Trends of obesity and underweight in older children and adolescents in the United States, Brazil, China, and Russia. Am J Clin Nutr. 2002;75:971-7.

6. Balaban G, Silva GA. Prevalência de sobrepeso em crianças e adolescentes de uma escola da rede privada de Recife. J Pediatr (Rio J). 2001;77:96-100.

7. Lobstein T, Baur L, Uauy R; IASO International Obesity Task Force. Obesity in children and Young people: a crisis in public health. Obes Rev. 2004;5 Suppl 1:4-104.

8. Stamler J, Dyer AR, Shekelle RB, Neaton J, Stamler R. Relationship of baseline major risk factors to coronary and all-cause mortality, and to longevity: findings from long-term follow-up of Chicago cohorts. Cardiology. 1993;82:191-222.

9. Poirier $P$, Lemieux I, Mauriege $P$, Dewailly $E$, Blanchet $C$, Bergeron J, et al. Impact of waist circumference on the relationship between blood pressure and insulin: the Quebec Health Survey. Hypertension. 2005;45:363-7.

10. Hirschler V, Aranda C, Calcagno ML, Maccalini G, Jadzinsky M. Can waist circumference identify children with the metabolic syndrome? Arch Pediatr Adolesc Med. 2005;159:740-4.

11. Reaven PD, Traustadóttir T, Brennan J, Nader PR. Cardiovascular risk factors associated with insulin resistance in children persist into late adolescence. Diabetes Care. 2005;28:148-50.

12. Marins JC, Giannichi RS. Avaliação e prescrição de atividade física: guia prático. 2 ed. Rio de Janeiro: Shape; 1998.

13. I Diretriz Brasileira de Prevenção e Tratamento da Síndrome Metabólica. http://www.sbh.org.br/download/DIRETRIZES_ SINDROME_METABOLICA_SBH_ORG_BR.pdf. Access: 30/10/2005.

14. Jessup A, Harrell JS. The metabolic syndrome: look for it in children and adolescents, too! Clin Diabetes. 2002;23:26-32.

15. American Diabetes Association. Standards of medical care in diabetes. Diabetes Care. 2005;28:S4-36.

16. CDC table for calculated body mass index values for selected heights and weights for ages 2 to 20 years. Developed by the National Center for Health Statistics in collaboration with the National Center for Chronic Disease Prevention and Health Promotion; 2000. Publicado em maio de 2002, modificado 20/04/2001. http://www.cdc.gov/growthcharts.

Access: 10/02/2006.
17. Huang TT, Johnson MS, Goran MI. Development of a prediction equation for insulin sensitivity from anthropometry and fasting insulin in prepubertal and early pubertal children. Diabetes Care. 2002;25:1203-10.

18. Després JP, Lemieux I, Tchernof A, Coullard C, Pascot A, Lemieux $\mathrm{S}$. Distribution et métabolisme des masse grasses. Diabetes Metab. 2001;27(2 Pt 2): 209-14.

19. Weiss R, Dziura J, Burgert TS, Tamborlane W, Taksali SE, Yeckcel $\mathrm{CW}$, et al. Obesity and the metabolic syndrome in children and adolescents. N Engl J Med. 2004;350:2362-74.

20. Isomaa $B$, Almgren $P$, Tuomi $T$, Forsen $B$, Lahti $K$, Nissen $M$. Cardiovascular morbidity and mortality associated with the metabolic syndrome. Diabetes Care. 2001;24:683-9.

21. Steinberger J, Daniels SR. Obesity, insulin resistance, diabetes, and cardiovascular risk in children: an American Heart Association scientific statement from the Atherosclerosis, Hypertension, and Obesity in the Young Committee (Council on Cardiovascular Disease in the Young) and the Diabetes Committee (Council on Nutrition, Physical Activity, and Metabolism). Circulation. 2003;107:1448-53.

22. Sung RY, Tong PC, Yu CW, Lau PW, Mok GT, Yam MC, et al. High prevalence of insulin resistance and metabolic syndrome in overweight / obese preadolescent Hong Kong Chinese children aged $9-12$ years. Diabetes Care. 2003;26:250-1.

23. Bao W, Srinivassan SR, Berenson GS. Persistent elevation of plasma insulin levels is associated with increased cardiovascular risk in children and young adults. The Bogalusa Heart Study. Circulation. 1996;93:54-9.

24. Pankow JS, Jacobs, Jr DR, Steinberger J, Moran A, Sinaiko AR. Insulin resistance and cardiovascular disease risk factors in children of parents with the insulin resistance (metabolic) syndrome. Diabetes Care. 2004;27:775-80.

25. Davis CL, Flickinger B, Moore D, Bassali R, Domel Baxter S, Yin $Z$. Prevalence of cardiovascular risk factors in schoolchildren in a rural Georgia community. Am J Med Sci. 2005;330:53-9.

26. Freedman DS, Dietz WH, Srinivasan SR, Berenson GS. The relation of overweight to cardiovascular risk factors among children and adolescents: the Bogalusa Heart Study. Pediatrics. 1999;103(6 pt 1):1175-82.

27. Cook S, Weitzman $M$, Auinger $P$, Nguyen $M$, Dietz WH. Prevalence of a metabolic syndrome phenotype in adolescents: findings from the third National Health and Nutrition Examination Survey, 1988 - 1994. Arch Pediatr Adolesc Med. 2003; 157:821-7.

28. Chu NF, Rimm EB, Wang DJ, Liou HS, Shieh SM. Clustering of cardiovascular disease risk factors among obese schoolchildren: the Taipei Children Heart Study. Am J Clin Nutr. 1998;67:1141-6.

Correspondence:

Aparecido Pimentel Ferreira

SCLN 106, Bloco A, Apto. 207

CEP 70742-510 - Brasília, DF - Brazil

Tel.: +55 (61) 3036.2811, +55 (61) 8143.8333

E-mail: aparecido@pos.ucb.br, cidopimentel@yahoo.com.br 